\title{
CONTENIDOS ORIENTALES EN LA POESÍA DE JOSÉ CORREDOR-MATHEOS
}

\author{
M. a Elena Rodríguez Ventura \\ UNIVERSIDAD DE LA LAGUNA
}

La poesía de José Corredor-Matheos comienza su andadura en 1953 con su obra Ocasión donde amarte y se detiene hasta el momento con Un pez que va por el jardín de 2007. En medio se suceden los siguientes libros: Ahora mismo (1960), Poema para un nuevo libro (1961, Premio Boscán de Poesía), Libro provisional (1967), Carta a Li-Po (1975), Y tu poema empieza (1987), Jardin de arena (1994) y El don de la ignorancia (Premio Nacional de Poesía, 2005). Entre el primero y el último, se da una continuidad o progresión evolutiva relacionada con la vida del autor. La constante de su poética y, por lo tanto, el motor de ésta es la búsqueda de la comprensión del mundo externo. A este respecto su obra ha sido dividida por la crítica ${ }^{1}$ en tres etapas: "Poesía de la vida cotidiana" en la década del 50, "Poesía de la existencia", década del 60 y "Poesía del

\footnotetext{
${ }^{1}$ J. M. ${ }^{a}$ Balcells, "José Corredor-Matheos y la poética del despojamiento" en J. M. ${ }^{a}$ Balcells (ed.), La escritura poética de José Corredor-Matheos, Ciudad Real, Ayuntamiento de Alcázar de San JuanDiputación provincial de Ciudad Real, 1996, pp. 71-96.
} 
despojamiento" a partir de 1975. La que aquí nos ocupa es precisamente esta última, que se inaugura con su obra Carta a Li-Po y se continúa con sus obras siguientes. Anteriormente a ésta el poeta es aquejado por las dudas existenciales, ansioso por encontrar un sentido a la relación entre el hombre y el mundo. Es entonces cuando entra en contacto con la espiritualidad oriental a través del hinduismo, con el Bhagavad-Gita, y la poesía china de la Dinastía Tang (618-910) a la que perteneció el poeta destinatario de su obra, Li-Po. Carta a Li-Po es el resultado de un cambio de actitud vital que da entrada a nuevos contenidos en su poesía. El poeta ahonda concienzudamente en el pensamiento oriental y se decanta por una de sus vertientes religiosas: el budismo zen. Toda la espiritualidad que emana de sus doctrinas se encuentra reflejada en los poemas orientales de su tercera etapa, que son sin duda los que hoy más singularizan al autor. Dedicaremos las páginas que siguen a interpretar los postulados más relevantes del zen, en relación siempre a los contenidos de los poemas de Corredor-Matheos.

\section{Desconceptualización ZeN}

La percepción de la realidad que el individuo experimenta en el día a día suele estar mediatizada o por sus sentimientos o por su propia mente que, en constante acción, está siempre cargada de pensamientos. Pocas veces fijamos la vista sobre cualquier elemento externo sin otra pretensión que la de verlo, es decir, sin que éste nos sirva de medio utilitario para nuestras reflexiones. Estamos más acostumbrados a percibir de un modo lógico-discursivo que intuitivo.

El pensamiento oriental, sin embargo, y en particular el zen, apuesta por una relación lo más directa posible con el mundo de los objetos, rechazando cualquier interferencia conceptual que interpongamos entre ambos. Lo que interesa es acceder a una realidad esencial y verdadera, sin tintes de subjetividad humana. Por este motivo, en el arte se intenta reflejar el resultado de una percepción intuitiva experimentada por el autor, que esté libre de interpretaciones racionales y que haya sido o esté siendo sentida en atención al objeto percibido en sí y no al individuo que percibe.

Corredor-Matheos, preocupado desde sus comienzos poéticos por la comprensión del mundo externo, da un salto importante en su tercera etapa y se adentra en esta perspectiva oriental que se descubre ante él como una posibilidad más certera. La intuición, que ya formaba parte de su concepción estético-vital, va 
a pasar a un primer plano con respecto a la razón y le va a llevar por caminos más hondos, en los que, sin embargo, prevalece una mayor claridad.

El Dr. Daisetz Suzuki, especialista en budismo y arte zen, habla de la diferencia que existe entre la percepción intuitiva y la percepción conceptual. Para ejemplificarla muestra dos poemas en los que sus distintos autores observan una flor:

Flor en el muro agrietado, te arranco de las grietas, te sostengo, raíz y todo, en mi mano, pequeña flor - pero si yo pudiera comprender lo que tú eres, raíz y todo, y todo en todo, podría conocer lo que Dios y el hombre son.

(Tennyson)

Observando de cerca, la nazuna está florecida en el seto.

(Basho)

Suzuki apunta que el poeta inglés Tennyson mantiene una "actitud completamente inquisitiva, filosóficamente hablando... ¿Tiene Basho la misma mente inquisitiva? No, su mente estaba lejos de ser así. En primer lugar, Basho nunca pensaría en arrancar inmisericordiosamente la pobre nazuna con "su raíz y todo" para sujetarla en su mano y preguntarle algo de sí mismo. Basho la conocía mejor que Tennyson. No era un científico empeñado en análisis ni en experimentos, ni era tampoco un filósofo. Cuando vio la nazuna con su flor blanca, tan humilde, tan inocente, y sin embargo con toda su individualidad, creciendo entre la vegetación circundante, al instante comprendió que la hierba no era distinta a él mismo." ${ }^{2}$ El interés de Tennyson no está en la flor como tal. Repara en ella sólo en base a su interés personal, que es el de reflexionar acerca de la existencia de Dios y del ser humano. Un poeta zen, como es Basho, lo que intenta es captar la esencia de la flor en sí; aprehender su mismidad, sin interferencias o vinculaciones personales que la aparten de lo que ella es realmente.

Sin embargo, más allá de detenerse a observar la naturaleza con mayor o menor atención, lo que persigue el zen es llegar a un estado mental determinado, a través del cual puedan establecerse relaciones de unidad casi

${ }^{2}$ D. Suzuki, El zen y la cultura japonesa, Barcelona, Paidós, 1996, p. 179. 
místicas con los demás componentes del universo. Se trata de un estado de súper conciencia que permite corroborar una de las sentencias más famosas del budismo: "el cielo y la tierra proceden de la misma fuente; las diez mil cosas y yo somos uno."

Para el zen el mundo está compuesto por una pluralidad que sigue un mismo movimiento o ritmo interno. Cada uno de sus elementos o fenómenos son entendidos no sólo como entes individuales sino como manifestaciones de un Todo orgánico. De esta forma, las diez mil cosas son una misma cosa, al tiempo que también son las diez mil cosas por separado y de manera individual. Al entrar en dicho ritmo interno la esencialidad de cada ser confluye, y se produce una identificación o sentimiento de unidad, que hace que las diferencias desaparezcan. Cuando un artista zen se interrelaciona con un objeto está siguiendo este principio: "Todo en Uno y Uno en Todo." ${ }^{4}$ Por esto, Basho, al contemplar la flor intuitivamente, sintonizó con su vida interna y experimentó su aprehensión; sintió la armonía existente entre ambos y, por lo tanto, existente en el Cosmos. Hay un ejemplo muy conocido del filósofopoeta Chuang-Tzu, uno de los padres del Taoísmo, que cuenta su experiencia. Veámosla a través de la versión de Octavio Paz:

Soñé que era una mariposa. Volaba en el jardín de rama en rama. Sólo tenía conciencia de mi existencia de mariposa y no la tenía de mi personalidad de hombre. Desperté y ahora no sé si soñaba que era una mariposa o si soy una mariposa que sueña que es Chuang-Tzu. ${ }^{5}$

El estado de unión al que accede el artista se produce gracias a una mente pura y transparente, pues sólo así puede hacerse partícipe de esta Verdad. Si la mente se encuentra repleta de complejidades intelectuales lo único que consigue es alejarse del verdadero ser y de las interiores pulsaciones que responden a su origen. Las ideas, los juicios, las expectativas, etc., gestados a través de la razón, han llenado un recipiente que antes estaba vacío (mente pura). Es necesario regresar al estado inicial en el que operan los demás seres para poder comulgar con ellos y recuperar así la identidad primera y esencial. El objetivo del zen no es otro que éste: "restaurar la experiencia de la inseparabilidad original", 6 es decir, retornar al Uno y al Todo.

${ }^{3}$ D. Suzuki, Budismo zen, Barcelona, Kairós, 2003, p. 55.

${ }^{4}$ D. Suzuki, El zen y la cultura japonesa, cit., p. 32.

${ }^{5}$ Octavio Paz, Chuang-Tzu, Madrid, Siruela, 2000, p. 53.

${ }^{6}$ D. Suzuki, El zen y la cultura japonesa, cit., p. 139. 
Los métodos utilizados por los maestros zen para eliminar el proceso analítico de la razón son de lo más insólitos. No se dedican a instruir a los discípulos con largos sermones llenos de teorías abstractas. Sus enseñanzas son eminentemente prácticas y suelen seguir dos caminos: uno verbal y otro basado en la acción. De lo que se trata es de alcanzar la mente en sí; la súper conciencia de la que hablábamos anteriormente, para poder armonizar con la Realidad.

El camino que hemos llamado verbal no atiende a las normas lógicas de la lingüística ya que intenta romper con el carácter conceptualizador de las palabras y del lenguaje. El método consiste en formular preguntas y obtener respuestas. Veamos un ejemplo de Xuedou, gran maestro y literato de los siglos XI y XII. Cuando alguien peguntó a Xuedou “¿Cuál es el sentido del zen?" , éste respondió: "Las montañas son altas; los océanos, profundos."7

Las respuestas son generalmente extrañas. A través de ellas se intenta modificar el mecanismo de pensamiento discursivo utilizado por el discípulo en sus preguntas. Las palabras del maestro interrumpen el movimiento de su mente y le acercan a una comprensión más interiorizada y profunda del mundo. Una comprensión que resulta inefable. Los maestros zen tienen un dicho: "Examina las palabras vivas y no las muertas." 8 Las palabras vivas son las que nos hacen despertar a una captación más inmediata de la realidad y nos apartan de lo que los maestros llaman "sonambulismo lógico-intelectual" (palabras muertas). El zen debe apuntar directamente a una mente libre y despojada de cuantos prejuicios haya adquirido, pues estos se comportan igual que una telaraña opaca que empaña sus alrededores.

El camino basado en la acción tiene el mismo fin. Hay múltiples narraciones o historias que cuentan cómo un maestro reprende a su alumno en el momento en que éste comienza un discurso intelectual. Generalmente les propinan algún golpe para que adquieran la comprensión verdadera de la que hablábamos en el párrafo anterior. Se trata de paralizar la sucesión de pensamientos que está produciendo en ese momento. Cuenta Suzuki que "cuando alguien preguntó a Rinzai cuál era la esencia de la enseñanza budista, el maestro bajó de su asiento y, agarrando al interlocutor por la parte delantera de su túnica, lo abofeteó y lo soltó." 9

7 Thomas Cleary, La sencia del zen (Los textos clásicos de los maestros chinos), Barcelona, Kairós, 2001, p. 37.

${ }^{8}$ D. Suzuki, El zen y la cultura japonesa, cit., p. 16.

${ }^{9}$ D. Suzuki, loc. cit. p. 16. 
La preocupación por alcanzar la captación inmediata de la realidad es algo que han tenido en cuenta también algunos autores de Occidente. Sin embargo, en este otro lado, sufrimos un mayor apego hacia la actividad intelectual y filosófica que hacia un modo de entendimiento más práctico o espontáneo. Nos falta tal vez la fe o confianza en esa especie de configuración cósmica que regula y mueve la existencia de todos. Nos cuesta tremendamente vivir por vivir, sin más. Pero surge el anhelo por conseguirlo, por ver un mundo latente al margen de la reflexión humana, y se ansía un mayor acercamiento a la naturaleza que nos circunda. Suzuki expone esta misma idea de la manera siguiente:

Por muy civilizados y educados que estemos en un entorno artificialmente inventado, todos parecemos poseer un innato anhelo de la primitiva simplicidad ligado a una forma de vida natural. De ahí la afición de los habitantes de las ciudades por las acampadas veraniegas en los bosques, los viajes por el desierto, o las excursiones por caminos nunca hollados. Con todo esto pretendemos por unos momentos sumergirnos en el seno de la Naturaleza y sentir directamente su pulsación...La vida, en sí misma, es bastante simple, pero al ser contemplada por el intelecto analizador puede ofrecer inigualables complejidades. Con todos los aparatos de que dispone la ciencia, no hemos sondeado todavía los misterios de la vida. Pero, una vez situados en su corriente, parecemos ser capaces de entenderlos, a pesar de su pluralidad y enmarañamiento aparentemente interminables. ${ }^{10}$

Hay un poeta que, sin llegar a conseguir embarcarse en esta corriente vital, toma conciencia de ella y se lamenta por la poderosa barrera que impone el intelecto, a través de la cual es imposible acceder a la naturaleza. Se trata de Alberto Caeiro, uno de los heterónimos del gran metafísico portugués Fernando Pessoa:

¿Quién me manda a mí querer entender? ¿Quién me dijo que había que entender? Cuando el verano me pasa por la cara la mano leve y caliente de su brisa, sólo tengo que sentir agrado porque es brisa o que sentir desagrado porque está caliente ${ }^{11}$

${ }^{10}$ D. Suzuki, Budismo zen, cit., p. 84.

${ }^{11}$ J. L. García Martín, Fernando Pessoa, Madrid, Júcar, 1983, p. 203. 
La percepción que persigue Caeiro es más sensorial que espiritual, lo cual la hace distinta a la propugnada por el zen, que implica, como hemos visto, la experiencia de la aprehensión y la unidad. La angustia que siente este poeta procede de la conciencia de saberse preso de si mismo; de no poder traspasar el límite de sus pensamientos. En otro poema dice: "Con filosofía no hay árboles: hay sólo ideas. / Hay sólo cada uno de nosotros, como una cueva. / Hay sólo una ventana cerrada, y todo el mundo allá fuera; / y un sueño de lo que se podría ver si la ventana / se abriera." ${ }^{12}$ El sueño del que habla Caeiro es el único tipo de percepción posible para él. Un maestro zen hizo esta misma observación mientras miraba una flor: "los hombres del mundo ven esta flor como en un sueño", ${ }^{13}$ queriendo decir que generalmente no mantienen una visión real.

La referencia a Caeiro no es arbitraria. Antonio Fernández Molina encuentra cierta similitud entre Corredor-Matheos y el heterónimo pessoano. Sin embargo, el primero está imbuido por el espíritu de la poesía china y ataja el problema a través de la sabiduría que ésta conlleva. El autor cuenta con la certeza de poder acceder a un estado natural que le permita una percepción real. No obstante, no es tarea fácil y Corredor-Matheos lo sabe. Su mente occidental soporta el peso de un raciocinio analítico mucho mayor que el que encontramos en el pensamiento oriental. Por eso, en sus primeros intentos la experiencia deseada no termina de cuajar y se repiten momentos como el que sigue:

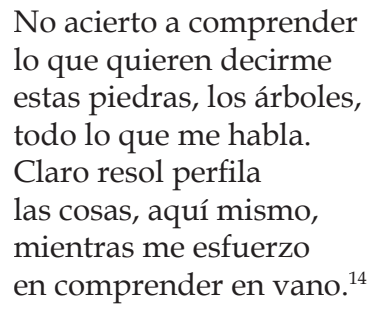

Desentenderse de la interpretación personal no es misión que pueda ser cumplida en cualquier instante, ni durar más que un instante. Hay momentos puntuales de concentración o meditación en los que la intuición gana y se superpone a la razón pero éstos son efímeros y requieren de una cierta predisposición. Es muy probable que el pensamiento irrumpa y lo estropee

12 J. L. García Martín, op. cit., p. 213.

${ }^{13}$ D. Suzuki, Budismo zen, cit., pp. 54-55.

${ }^{14}$ J. Corredor-Matheos, Carta a Li-Po, en Poesía (1970-1994), Pamplona, Pamiela, 2000, p. 49. 
todo. Octavio Paz dice en un ensayo que "el remedio contra la sensación y su dispersión instantánea es la reflexión. Entre una sensación y otra, entre un instante y otro, la reflexión interpone una distancia que es también un puente: una medida." 15 Tal puente o medida se traduce en el intento por comprender lo que ocurre en la experiencia de la captación real. Pero es esta pretensión, que aparentemente se encamina hacia la claridad, lo que la tuerce hacia el lado contrario: donde la oscuridad.

El poeta norteamericano William Carlos Williams, con quien CorredorMatheos presenta cada vez más afinidad, negaba también la utilidad de los pensamientos a la hora de captar los objetos. El fin era conseguir que hablasen por si mismos; la captación en favor del objeto en sí. Pero esto sólo ocurre cuando cesan las ideas sobre ellos. Su técnica de creación, tal y como lo requerían los imagistas, consistía en observar sin comentarios. El estudioso Kenneth Burke define así este proceso: “Aquí está el ojo, ahí está la cosa sobre la que el ojo se detiene. Lo que transcurre mientras dura esa relación entre uno y otra, eso es el poema." ${ }^{16} \mathrm{El}$ resultado es la expresión directa de una sensación concreta, experimentada como impresión súbita por el autor:

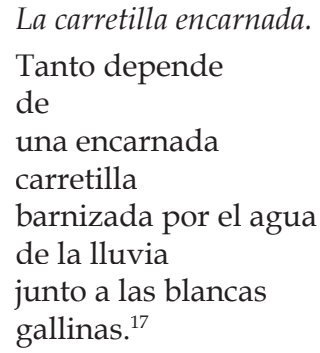

Este despojamiento en la expresión, como si se hubiese podado el lenguaje sobrante del poema, es una característica, como hemos visto, de la escritura de Corredor-Matheos. Tanto él como el norteamericano desnudan sus versos en busca de claridad, transparencia y esencialidad. Por supuesto no se trata de un recurso meramente estético, pues surge de forma paralela al modo de entender la relación del hombre con el mundo que le rodea.

\footnotetext{
${ }^{15}$ Octavio Paz, Los hijos del limo, Barcelona, Seix Barral, 1987, p. 172.

${ }^{16}$ J. M. Brinnin, Tres escritores norteamericanos VII, John Crowe Ranson, Ezra Pound, William Carlos Williams, Madrid, Gredos, 1965, p. 127.

${ }^{17}$ J. M. Brinnin, op. cit., p. 138.
} 
El autor manchego utiliza con frecuencia en sus poemas la imagen del agua que limpia. Se trata de una limpieza metafísica que deja ver el lado más profundo y esencial de la naturaleza: "Ha limpiado la lluvia / lo que impedía al pino, / el ciprés, / la morera y el sauce / darnos su olor. El agua / ha refrescado el aire / y ha dejado el paisaje / transparente."18 La suciedad eliminada por este agua equivale al pensamiento. Cuando se desvanece, los ojos pueden ver con transparencia un asombroso mundo nuevo. Tras un verso como éste: "Un pensamiento solo / que corre hacia la muerte," ${ }^{19}$ el poeta entra en contacto directo con la experiencia de la identificación total: "Absorto ante las aguas / olvido mis preguntas / yo soy árbol, montaña, / yo soy río y olvido." ${ }^{20}$ El maestro zen Hongzhi de la dinastía song (960-1279) expresa esto mismo a modo de precepto: "debes sacudir el polvo y la suciedad de tus pensamientos subjetivos. Si el practicante lo logra, alcanzará un zen carente de esfuerzo en el que solamente hay una conciencia espontánea y panorámica." 21

Hemos de vaciar cuantos prejuicios hayamos acumulado a lo largo de la vida: ideas, conceptos, valoraciones personales..., y hemos de recuperar la naturalidad y espontaneidad de quien ve por primera vez. Los niños son un buen ejemplo de este tipo de percepción. Corredor-Matheos lo advierte: "tenemos que ser como niños." 22 Hemos de liberarnos de la determinación de la razón, que todo lo juzga. Uno de los poemas de Carta a Li-Po refleja la mirada de su hijo; podemos percibir de él una motivación auténtica y desinteresada, lo que propicia su respuesta inmediata:

Mi hijo, el más pequeño, mira de pronto el sol, que le pone en los ojos toda la luz del mundo. Sonríe muy feliz, $\mathrm{y}$, durante un instante, todo se ha detenido ante el prodigio. ${ }^{23}$

\footnotetext{
${ }^{18} \mathrm{~J}$. Corredor-Matheos, op. cit., p. 56.

${ }^{19} \mathrm{~J}$. Corredor-Matheos, op. cit., p. 46.

${ }^{20}$ J. Corredor-Matheos, op . cit., p. 53.

${ }^{21}$ Thomas Cleary, La esencia del zen, op . cit., p. 182.

${ }^{22}$ Santiago Martínez, "Corredor-Matheos, sin metáforas”, Barcelona, La Vanguardia, 27 de octubre de 2004, p. 12.

${ }^{23}$ J. Corredor-Matheos, op. cit., p. 88
} 
La presencia infantil es común en sus poesías y refleja una especial atención a este mundo en su vida real y cotidiana. Recordemos su estudio u homenaje a la infancia titulado El juguete en España (1989), o los poemarios dedicados a sus nietas: Canciones para Judit y Canciones para Marta (1998 y 2000 respectivamente). El autor simpatiza con esta etapa de la vida porque la reconoce como más pura y cercana a la esencialidad del ser. Asimismo, Suzuki, en su estudio El zen y la cultura japonesa, habla de un tipo de vida libre y natural. El especialista hace referencia a un monje budista del Japón llamado Ryokwan (1758-1831) que llevó una vida tan espontánea y carente de pretensiones como la de un niño. Y justifica su asociación de esta forma:

Ser natural significa, por consiguiente, ser como un niño, aunque no necesariamente con la simplicidad intelectual de un niño o su crudeza emocional. En cierto sentido, un niño es un conglomerado de impulsos egoístas, pero en su afirmación de éstos es completamente natural, no tiene escrúpulos ni hace cálculos en cuanto a consideraciones prácticas y méritos o desméritos mundanos... Ignora todas las artimañas y engaños sociales que practican todos los adultos decentes, convencionales y respetuosos con las leyes. No vive bajo constricciones artificiales, inventadas por los humanos. ${ }^{24}$

Digamos que los niños, en cierto modo ajenos a condicionamientos sociales y a la necesidad de ahondar en cuestiones de carácter existencial, presentan motivaciones y actuaciones aparentemente más auténticas y sencillas que los adultos, y por eso se acercan, más que éstos, al ritmo vital de la naturaleza. Los adultos están llenos de propósitos y Suzuki dice "ser libre significa falta de intención." ${ }^{25}$ Cuando la percepción es libre, es decir, carece de intención, volvemos a nuestra naturaleza esencial. Todo esto es fundamental en el arte, como decíamos, pues el creador ha de encontrarse en un estado espiritual libre de cualquier propósito preconcebido. Corredor-Matheos comparte, como veremos, dicho postulado. Uno de los poemas de Carta a Li-Po ejemplifica con mucha claridad todo lo expuesto hasta el momento. Está dedicado al matrimonio de pintores catalanes, amigos suyos, Albert Ràfols y María Girona, que pertenecieron al grupo artístico Els Vuit en el año 1946, compuesto por seis artistas más de vanguardia: el poeta Jordi Sarsanedas, el escultor Miguel

${ }^{24}$ D. Suzuki, El zen y la cultura japonesa, op. cit., p. 250.

${ }^{25}$ D. Suzuki, op. cit., p. 251. 
Gusils, los pintores Joan Palá, Ricardo Lorenzo y Vicenç Rossell, y el músico Joan Comellas. Corredor-Matheos ha hecho además un estudio sobre la obra de María Girona que lleva como título su mismo nombre.

\author{
La pintura está ahí. \\ No preguntes qué es. \\ Si intentas apresarla \\ se escurre entre los dedos. \\ Si quisiera explicártela \\ no hallaría palabras. \\ Confórmate con ver \\ lo que tus ojos miran, \\ y no busques razones, \\ que no las necesitas. \\ Abandona los ojos, \\ pon en paz los sentidos \\ y recoge el espíritu \\ para un largo viaje. \\ Hoy, un aroma nuevo \\ ha perfumado el aire. \\ Tú abre bien los ojos, \\ pero no hagas preguntas. ${ }^{26}$
}

A Albert Ràfols y María Girona

\title{
ILUMINACIÓN O SATORI.
}

La filosofía del zen consiste en ver directamente el misterio de nuestro propio ser, que de acuerdo al zen, es en sí mismo la Realidad. El zen nos aconseja así no seguir la enseñanza verbal o escrita del Buda, no creer en otro ser supremo que en uno mismo, no practicar métodos ascéticos de aprendizaje, sino llegar a una experiencia interior que debe surgir de lo más recóndito y profundo de nuestro ser. Ésta es una apelación a un modo intuitivo de comprender, que consiste en experimentar lo que en japonés se conoce como satori (wu en chino). ${ }^{27}$

La iluminación o satori ( $w u$ en chino) es un estado de conciencia en el que el sujeto alcanza la totalidad del ser, es decir, conecta de una manera profunda y espiritual con todos los seres que conforman la Realidad. Si tenemos en cuenta

\footnotetext{
${ }^{26}$ Véase Carta a Li-Po, p. 55.

${ }^{27}$ D. Suzuki, El zen y la cultura japonesa, cit., p. 148.
} 
que cada uno de los elementos del Cosmos se encuentra en los demás (recordemos la máxima "Todo en Uno y Uno en Todo" que esbozábamos en el apartado anterior), el sujeto será capaz de realizar a un tiempo tanto su identidad como su alteridad. Vivir esta experiencia constituye el fin último del zen. Ya desde las enseñanzas de Buda, procedentes de la India, se incidía en esta idea. Así como Buda, el Iluminado, consigue estar en cada uno de los diez mil seres, el hombre zen tendrá como objetivo identificarse e incluso transmutarse en todo cuanto le rodee. Habrá de conectar con una especie de esfera comunitaria en la que se encuentra el misterio y significado de la vida, que es la Unidad. Los seguidores del budismo, a partir de esta creencia, sienten un fervoroso respeto por todo cuanto pertenece a la naturaleza, pues en cualquiera de sus elementos se halla la naturaleza de Buda, la naturaleza de sus parientes más cercanos, la naturaleza de ellos mismos. Existe a este respecto un dicho de un monje-estudioso llamado Sojo (384-414) que dice lo siguiente: «El cielo, la tierra y yo tenemos una misma raíz,/ las diez mil cosas y yo somos una misma sustancia. $»^{28}$

En esto consiste la iluminación, en recuperar la unión original con el universo. De acuerdo con el zen cualquier persona tiene la capacidad de estar iluminada; a través de los libros o los maestros se puede encontrar el camino pero la realización de la experiencia en sí depende siempre de uno mismo. Nadie más puede dárnosla. Suzuki expone a este respecto una enseñanza en la que coinciden tanto Buda como otros maestros: "No dependas de los otros, ni de la lectura de sutras y sastras. Sé tu propia lámpara." ${ }^{29}$ En un poema de Carta a $\mathrm{Li}$-Po, Corredor-Matheos se encuentra buscando su iluminación pero ésta no aparece. En los últimos versos dice: "Yo escucho lo que suena/ en mi interior. / Pero no basta así. / Enciendo al fin mi lámpara, / y voy hacia mi casa / silbando, por si acaso." ${ }^{30} \mathrm{El}$ poeta sabe que en su empeño por buscarla se desvía del camino. La iluminación es algo que llega por sorpresa cuando no hay en el interior ningún tipo de pretensión, cuando la meditación acalla los pensamientos y la mente despejada se mantiene atenta únicamente a la percepción del momento presente. Por eso toma la determinación de irse "silbando", es decir, haciéndose el despistado "por si acaso". En este sentido, el final resulta un tanto humorístico. El poema no refleja su satori pero sí la propuesta de cómo conseguirlo.

${ }^{28}$ D. Suzuki, op. cit. p. 235.

${ }^{29}$ D. Suzuki, op. cit. p. 17.

${ }^{30}$ J. Corredor-Matheos, op. cit., p. 49. 
Generalmente el artista zen intenta reflejar en su obra la experiencia de la iluminación. Se trata de dotarla del ritmo espiritual con el que él ha conectado. Se habla de identificación e incluso de transmutación entre el sujeto creador y el objeto que se va a representar. En referencia a la pintura china Suzuki cita a Georges Duthuit, autor de Chinese Mysticism and Morden Painting, que apunta lo siguiente:

Cuando los artistas chinos pintan, lo importante es la concentración de pensamiento y la pronta y vigorosa respuesta de la mano a la voluntad que la dirige. La tradición les ordena ver, o más bien sentir, como un todo la obra que va a ser realizada antes de embarcarse en ella... El que reflexiona y mueve su pincel empeñado en pintar, se equivoca en grado sumo respecto al arte de pintar... Dibuja bambúes durante diez años, conviértete en bambú y, después cuando estés dibujando, olvida todo lo que sabes sobre los bambúes. ${ }^{31}$

Lo mismo ocurriría en poesía, y con una resolución muy distinta a lo que veíamos en el poema anterior, Corredor-Matheos expone lo siguiente en otro poema de la misma obra: "Mi cuerpo es ese árbol, / la montaña y el río. / Nadie, nadie lo sabe: / sólo yo, que lo olvido." 32

El proceso de creación que sigue tanto el artista chino como el poeta manchego sería más o menos como sigue: el sujeto creador se adentra en el objeto contemplado y siente su naturaleza interna, a continuación se diluye en un estado original del que ambos forman parte y en el que cualquier identidad es anulada u olvidada, incluso la del propio creador.

La crítica parece estar de acuerdo en que la identificación hombrenaturaleza que se da en los poemas corredorianos, sirva de ejemplo el poema anteriormente expuesto, coincide con el satori, resultado de la contemplación mística en la que el objeto es aprehendido. José María Balcells afirma que "nos hallamos ante una suerte de ejercicio espiritual que radica en el concepto zen del satori o iluminación, que estriba en adentrarse en el ser de las cosas y en descubrir, allí, la irrealidad personal del yo." ${ }^{33}$ A su vez, detecta un mayor ahondamiento en esta experiencia a partir del libro $Y$ tu poema empieza, ya que en Carta a LiPo, su primer libro oriental, todavía son frecuentes los momentos en que la

\footnotetext{
${ }^{31}$ J. Corredor-Matheos, op. cit., p. 93.

32 J. Corredor-Matheos, op. cit., p. 106.

${ }^{33}$ J. M. ${ }^{a}$ Balcells, “José Corredor-Matheos y la poética del despojamiento”, en J. M. a Balcells (ed.), op. cit., p. 89.
} 
aprehensión se resiste. Una inadecuada predisposición del espíritu hace que el autor no consiga sintonizar con el mundo exterior y entonces surgen versos como estos: "Hoy el día es pesado, / y mi cuerpo, de plomo / derretido. / Levantaría el vuelo, / . . / pero no tengo fuerzas / y puede más que yo / todo el peso del mundo / colgado de mi túnica." 34 José María Sala Valldaura señala el contraste entre estos dos sentimientos: el de la identificación y el de su imposibilidad: "se trata de una necesaria contradicción en el intento de captar, mediante el lenguaje poético y la propia experiencia vital, las cosas: he aquí, en síntesis, el núcleo temático de Carta a Li-Po." ${ }^{\prime 35}$ Sin embargo, en sus siguientes obras, como diría Manuel Mantero, "la identidad sujeto-objeto va a conseguirse" ${ }^{136}$ Los nuevos poemas dejan ver una fusión más directa con la naturaleza: "Ahora sabes quién eres: / eres tomillo, espliego, / aquel arbusto / cuyo nombre no importa." ${ }^{37}$

Para alcanzar el satori es necesario que los seres, sujeto y objeto, se reconozcan de manera recíproca. Suzuki lo ejemplifica así: "Cuando veo una flor, no sólo debo verla yo a ella, sino que también ella debe verme a mí." ${ }^{38} \mathrm{~A}$ través de esta relación mutua, cada ser abandona su identidad individual y pasa a formar parten de una entidad mayor en la que el ser y el no-ser son lo mismo: "la flor se disuelve en algo superior a una flor y yo me disuelvo en algo superior a un objeto individual." ${ }^{39}$ En este estado se produce un despertar, una intuición sobre lo que realmente somos y se esclarece el misterio de la vida: "Cuando tiene lugar una mutua identificación, la flor es yo mismo y yo soy la flor." ${ }^{40}$

$\mathrm{Al}$ artista zen se le requiere entrar en íntima relación con el objeto antes de ser representado, es decir, ha de sentirse en unidad con él. Es común contar historias o anécdotas acerca de cómo el artista acude a un maestro en busca del espíritu zen para poder realizar su obra. Suzuki cuenta la siguiente:

Uno delos maestros Kano fue requeridoen una ocasión con objeto de pintar un dragón en el techo de uno de los principales edificios pertenecientes a Myosynki...El pintor recurrió....al abad de un monasterio zen, un gran maestro de aquella época, y le preguntó sobre la forma de proceder en su trabajo. El maestro le dijo simplemente: "Conviértete en dragón."

\footnotetext{
${ }^{34}$ J. Corredor-Matheos, op. cit., p. 83.

${ }^{35}$ J. M. ${ }^{a}$ Sala Valldaura, "José Corredor-Matheos, poeta”, en J. M. ${ }^{a}$ Balcells, op. cit., p. 117.

${ }^{36}$ M. Mantero, “La poesía de Corredor-Matheos (Desde las manos), en J. M. ${ }^{a}$ Balcells, op. cit., p. 149.

${ }^{37}$ J. Corredor-Matheos, op. cit., p. 117.

${ }^{38}$ D. Suzuki, Budismo Zen, op. cit., p. 54.

${ }^{39}$ D. Suzuki, Budismo Zen, op. cit., p. 56.

${ }^{40}$ D. Suzuki, Budismo Zen, op. cit., p. 54.
} 
El artista kano no acabó de entender cómo debía interpretar el consejo, pero tras mucha reflexión, la idea comenzó a ser comprendida. Cuando finalmente regresó a donde estaba el maestro, no era ya un simple artista tratando de pintar n dragón, sino el propio dragón...Se trataba, pues, de un dragón pintándose a sí mismo, no de un artista humano tratando de representar una criatura mítica. ${ }^{41}$

Se produce, como vemos, una transmutación, que es algo más que una identificación. A través del inconsciente podemos percibir una identidad común a todos los seres del universo que es la que permite la mutación entre ellos; el reconocimiento de cada uno en el otro. Cuando todas las diferencias individuales quedan anuladas, los seres se funden en algo mayor y se manifiestan como una sola unidad. Si un artista se siente inmerso en este nivel común la obra resultante será algo así como un microcosmos que refleje la acción del gran macrocosmos vital.

El arte oriental, en general, es misterioso y sugerente ya que se presta a desvelar profundos conocimientos como éste. De igual modo, podríamos decir que todas las literaturas místicas de occidente, puesto que parecen querer transmitir alguna verdad oculta y fundamental sobre la existencia del hombre, contienen ese alo misterioso o enigmático. Recordemos en España al místico San Juan de La Cruz y el sentimiento de unidad espiritual con Dios que reflejaba en sus poemas. Su experiencia era expuesta paso a paso o vía a vía: purgación, iluminación y unión. La experiencia zen, sin embargo, no especifica cada paso, ya que se considera un error pararse a reflexionar acerca de ella, y tampoco se centra más que en un solo estado: el satori, que englobaría tanto la iluminación como la unión. Puesto que se trata simplemente de despertar algo que ya existe en nosotros no hay necesidad de seguir ningún camino ascético. En poesía la composición que representa directamente la experiencia zen es el haiku. En el poema de Basho ya citado anteriormente: "El viejo estanque, ¡ah! / salta una rana: / ¡el sonido del agua!," Suzuki explica que el poeta "percibió el universo entero. No sólo la totalidad del entorno quedó absorbido en el sonido desvaneciéndose en él, sino que el propio Basho quedó completamente anulado de su conciencia. Ambos, el sujeto y el objeto... dejaron de ser algo que se confronta y se condiciona recíprocamente." 42 Por eso, estas composiciones pueden mostrar la vuelta del ser a la naturaleza.

${ }^{41}$ D. Suzuki, Budismo Zen, op. cit., p. 106.

${ }^{42}$ D. Suzuki, El zen y la cultura japonesa, op. cit., p. 155. 
Corredor -Matheos siente algo, si no igual, muy parecido. En su obra poética, también de carácter sugerente, unas veces esboza su experiencia detenidamente y otras deja sólo una pequeña huella de dicho sentimiento a modo de haiku. Veamos un ejemplo de cada uno:

Un árbol no es un árbol, ni un insecto un insecto, ni una piedra una piedra. $Y$ los ves transformarse, ser una cosa y otra, sin dejar de ser eso: árbol, insecto, piedra. ¿Por qué tú has de ser tú? Oyes crecer la tarde, vertical como un árbol, leve como un insecto, dura como una piedra, y tú eres el vacío en el que todo cabe, el vacío que queda cuando dejas que todo sea tal como es: árbol, insecto, piedra. ${ }^{43}$ Ryoan-ji, Kyoto

Jardín de arena.

Con las últimas lluvias, flores de piedra. ${ }^{44}$

En el primero, de $Y$ tu poema empieza, el poeta siente al tiempo que expone. Ese "tú," que es en realidad él mismo, se diluye al igual que los otros elementos de la naturaleza, y se reconoce como continuación de ésta. Cada uno, perteneciente a un estrato diferente: vegetal, animal y mineral, simultanea su identidad del ser con la del no-ser. Y entran en ese estado superior que el poeta llama simbólicamente "la tarde,"y que también ha adquirido los rasgos de sus congéneres: "vertical", "leve" y "dura." Cuando todo se unifica, las diferencias desaparecen y el vacío invade cualquier presencia, incluida la del propio

${ }^{43}$ J. Corredor-Matheos, op. cit., p. 127.

${ }^{44}$ J. Corredor-Matheos, op. cit., p. 226. 
creador. El concepto del vacío en oriente es de importancia capital para entender el universo; hablaremos de él más ampliamente en las páginas que siguen.

El segundo poema es uno de los siete haikus incluidos en el libro Jardín de arena. Está dedicado al templo zen llamado Ryoan-ji, de finales del siglo XV, en el que se encuentra precisamente uno de los jardines más representativos del tipo de jardín kare-sansui o jardín seco. Se trata de un espacio austero y sobrio, de reducidas dimensiones, en el que apenas hay más que arena, rocas y algún que otro atisbo de vegetación. Su función es incitar a la meditación. Es muy probable que Corredor-Matheos lo haya visitado en su viaje a Kyoto de 1992, época en la que además escribe sus haikus. Éste, en particular, refleja de nuevo el fenómeno de la transmutación; las flores adquieren la esencia de las piedras y viceversa. Todo esto se produce a través de "la lluvia," imagen de connotaciones muy parecidas a las de "la tarde" del poema anterior. "La lluvia" deja al descubierto, con un efecto purificador, la esencialidad de la naturaleza, sólo perceptible en su estado inicial de unidad suprema. A diferencia del primer poema el yo poético o sujeto contemplador está ausente; ni siquiera aparece la segunda persona del singular "tú", como desdoblamiento de la primera. El caso es que el haiku, transmisor del zen, rechaza cualquier manifestación del ego, pues ésta supone una interferencia en la aprehensión de la mismidad: esencia de la Realidad exterior. El poeta desempeña el papel de observador silencioso y permanece alerta al misterio de la vida; cuando conecta con él se mueve en armonía junto a las demás cosas y se descubre a si mismo palpando su verdadera esencialidad.

En los haikus de Basho nunca aparece el yo poético. El poeta japonés opera desde un estado de conciencia que es colectivo, no individual. Se trata de una especie de inconsciente cósmico al que están conectados todos los seres. Por eso sobre su más famoso haiku Suzuki explica que "el estanque era el estanque, Basho era Basho, la rana era la rana; permanecían tal como eran o como habían sido desde el pasado sin comienzo. Pero Basho no era distinto del estanque cuando miró hacia él, ni era distinto de la rana cuando escuchó el ruido del agua producido por su salto. El salto, el ruido, la rana, el estanque y Basho, estaban solos en uno y uno en todos. Había una absoluta totalidad, es decir, una absoluta identidad, o, para hacer uso de la terminología budista, un perfecto estado de Vacuidad." ${ }^{45}$ Resulta curioso observar cómo, por este motivo, el artista zen nunca muestra un especial interés por protagonizar su

\footnotetext{
${ }^{45}$ D. Suzuki, Budismo Zen, op. cit., pp. 127-128.
} 
obra. Lo que persigue, al eliminar las diferencias, es la liberación de su yo individual para ser incluido en la totalidad.

Corredor-Matheos no es ni oriental ni budista pero participa del contenido más esencial del zen. Su mente occidental leimposibilita muchas veces la anulación del yo, que asoma honestamente en la mayoría de sus poemas, incluso en algunos haikus. Eso sí, según avanza su producción, el yo poético se transforma en "tú", lo que indica cierto distanciamiento de si mismo, a medio camino de su liberación total: "Como en tus versos, / en el paisaje sale / la luna nueva." ${ }^{46}$ Muchos de sus poemas de Carta a Li-Po podrían derivar en un haiku al estilo Basho ya que parecen describir el camino que lleva a la autoanulación y, en consecuencia, al sentimiento de unidad o satori. El siguiente poema alude al famoso haiku de Basho y a dicho sentimiento, pero también a la imposibilidad de alcanzarlo:

Los árboles, el cielo, las aguas del estanque. Un sentimiento nuevo puede romperlo todo, dispersar las estrellas, abrir grietas al mundo. Pero mi corazón seguirá, para siempre, contando los segundos, descontando los segundos. ${ }^{47}$

El vacío ZeN

$$
\begin{aligned}
& \text { Ese silencio, ¿dónde, } \\
& \text { dónde lo oí yo antes? } \\
& \text { ¿Un día ya lejano, }{ }^{88} \\
& \text { cuando salía el sol } \\
& \text { y era todo muy tierno, } \\
& \text { recién nacido el mundo? }
\end{aligned}
$$

El concepto de "nada" o "vacío" aparece ya desde el siglo XII a. C. recogido en el I Ching (Libro de las mutaciones), un libro anónimo de sabiduría china que indica normas de conducta sabias para la vida. Sin embargo, quienes convierten el

\footnotetext{
${ }^{46} \mathrm{~J}$. Corredor-Matheos, op. cit., p 230.

${ }^{47}$ J. Corredor-Matheos, op. cit., p. 38.

${ }^{48}$ J. Corredor-Matheos, op. cit., p. 69.
} 
"vacío" en elemento central de su sistema filosófico y religioso son los taoístas y, a través de ellos, los grandes maestros del budismo Chan (Zen) a partir de la dinastía Tang (S. VII-IX). Para entender la importancia del "vacío" tanto en el taoísmo como en el pensamiento zen hemos de explicar, aunque sólo sea levemente, lo que para ellos sería la configuración del universo y el mecanismo que lo rige.

Se concibe el Universo en base a la ley de la polaridad, a través de la cual la existencia de los fenómenos se explica en función de un opuesto, que le sirve de complemento. Así por ejemplo, la luz se entiende sólo porque existe la oscuridad, la belleza en función de lo feo, la vida en relación a la muerte, etc. Ningún elemento existe de manera individual sino dependiendo de su otro. Pero la relación entre opuestos no es sólo de dependencia sino también de interacción mutua pues cada cual puede transmutar en el otro. De esta forma, el universo, sin dejar de ser una Unidad o un Todo orgánico, está en incesante movimiento. Se producen cambios constantemente, como el cambio de las estaciones, por lo que el mundo natural, lejos de permanecer intacto, se constituye en base a un continuo fluir. Las metamorfosis se producen gracias a dos fuerzas o alientos vitales llamados yin y yang, que poseen todos los seres que componen el mundo. El yin es la fuerza receptiva y el yang la fuerza activa; la constante interacción que hay entre ambas hace posible la transmutación. Ahora bien, tal interacción se da en un estado intermedio que existe entre ambos, que permite la disolución de cada elemento antes de transmutarse en otro. Este estado intermedio es el vacío. Su importancia es capital pues sin él los opuestos chocarían se manera rígida.

Donde mejor queda ejemplificado el efecto del vacío, como elemento mediador, es en el arte pictórico. Es frecuente encontrar cuadros paisajísticos chinos en los que las montañas y los ríos son separados por una especie de niebla que al mismo tiempo los une. Ambos elementos parecen disolverse en ella. De esa forma la montaña puede hacerse río y el río puede hacerse montaña. La oscilación entre los dos polos es tarea de la misteriosa niebla, es decir, del vacío. A través de él cualquier elemento puede erigirse en el otro. Y son estas relaciones entre los distintos elementos de la naturaleza las que propician un sistema de perfecta armonía cósmica. Observemos un cuadro de estas características, perteneciente al pintor de la dinastía Qing, Shitao (16411701), que se titula "La cascada en el monte Lou." 49

\footnotetext{
${ }^{49}$ François Cheng, Vacío y plenitud, Madrid, Siruela, 1993, lámina 12, pp. 64-65.
} 


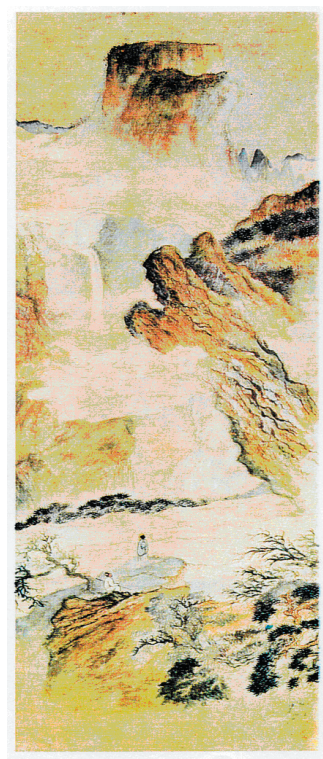

Corredor-Matheos habla de esta fenomenología en sus poemas. Observemos uno en el que, casualmente, alude a la pintura. Está dedicado al pintor de posguerra Manuel Viola (Zaragoza, 1919), amigo suyo durante los años 58 o 59 y 63, que perteneció al grupo madrileño El Paso junto a otros artistas como Saura, Canogar, Millares, Feito. Todos defendían una especie de arte metafísico. Corredor-Matheos ha escrito bastante sobre él y en un artículo titulado "Como un meteoro" ha dicho lo siguiente:

Estos relámpagos de su pintura alumbran la noche oscura de lo que puede ser el alma con una espontaneidad absoluta...La luz y la sombra se despeñan desde lo alto, en una cascada que nos puede segar. Percibimos que esta aventura es la nuestra, que en esta caída o ascensión, estamos directamente implicados. Hay aquí un aliento poderoso, que da ganas de llamar metafísico, palabra que puede ayudarnos a comprender esta ansia ilimitada de fusión con el universo..$^{50}$

Como veremos la dedicatoria no es gratuita, pues el poema encierra esta misma concepción estético-vital que pintor y poeta parecen compartir:

\footnotetext{
${ }^{50}$ J. Corredor-Matheos, “Como un meteoro" en Manuel Viola, Madrid, Guadalimar, 1987, p. 10.
} 


\section{Al pintor Viola}

Tú, hoy, nos has mostrado

el vacío universo

a la luz de un relámpago.

El pincel nos repite:

sombra y luz son lo mismo.

Y clavas el cuchillo

en donde más nos duele.

Cuando llega la noche

charlamos y bebemos

hasta la madrugada,

a la luz de tus cuadros..$^{51}$

En este poema Corredor-Matheos nombra el vacío como si hablase de una gran verdad que resplandece y da respuesta al misterio de la vida. El pincel, es decir, la mano del pintor estaba en posesión de tal revelación en el acto creativo, pues ha reflejado el principio de polaridad que iguala sombra y luz, y ha recordado con ello que el mundo de lo diverso o lo diferente es en realidad Uno. Las diferencias confluyen y desaparecen, y en el vacío está la clave.

Los últimos versos recuerdan a los homenajes o poemas de la amistad que escribían los poetas Tang, especialmente Li-Po. En uno de ellos titulado "Una noche entre amigos" el poeta chino dice: "Para ahuyentar las eternas tristezas del mundo, / nos entregamos a beber, centenares de jarras. / La hermosa noche nos invita a íntimos coloquios, / y la brillante luna nos quita el sueño." 52

El vacío mantiene además una relación directa con el origen del universo. Si atendemos a la ley de la polaridad, en un principio u origen habría de encontrarse la contraposición entre el mundo de lo definido o visible y el mundo de lo indefinido o invisible. De este modo, el vacío no sólo constituiría el elemento a través del cual se relacionan las cosas sino también constituiría el origen de esas cosas. Chantal Maillard, en un estudio titulado "Expresar el vacío" lo ha explicado de la siguiente forma:

El vacío ocupa las formas, les da vida. Del uno (soplo original) sale el dos: el yin (fuerza receptiva) y el yang (fuerza activa); y entre el yin y el yang actúa el tres: el soplo o vacío mediador que procede del vacío original y que pone a los opuestos en movimiento dando lugar a los

\footnotetext{
${ }^{51}$ J. Corredor-Matheos, op. cit., p. 108.

${ }^{52}$ Chen Guojian, Li Po, Cien poemas, Barcelona, Icaria, 2002, p. 105.
} 
10.000 seres. Este vacío mediador mantiene a los seres en relación con el vacío supremo... ${ }^{33}$

Si todos lo seres albergamos el Uno o Todo primordial, también habremos de albergar el vacío primordial. Es aceptada por igual la existencia del mundo de lo visible y el mundo de lo invisible, por lo tanto, en lo que atañe al hombre, esta doble naturaleza le hará partícipe de un ser y un no-ser que habitan en su interior. El concepto del vacío se sostiene en la rotación de ambos; el paso del ser al no-ser y viceversa. Esta idea no sólo aparece en la obra poética oriental de Corredor-Matheos, como veremos, sino también en otros libros como Metamorfosis Ponç-Kafka de 1978, en el que, a propósito de la obra pictórica de Ponç, pintor catalán y amigo suyo, nos dice: “Éste nos describe un mundo en metamorfosis constante: nada es esto o aquello, sino el paso de una forma a otra. Sólo puente: tránsito de algo inexistente a otro ser o cosa también inexistente, que estalla con estruendo." ${ }^{54}$

La resolución al problema existencial de Corredor-Matheos reflejado en su "poética de la existencia" de los años 50 y 60, se encuentra en la aceptación de estas doctrinas, pero sobre todo, en la aceptación de la existencia de un vacío o una nada que todo lo invade, incluso al propio yo o ser individual. La mayoría de los poemas pertenecientes a su tercera etapa, la de corte orientalista, tienen alguna referencia al vacío. En ellos, el autor niega de manera sistemática todo cuanto observa, incluyéndose a sí mismo como punto culminante:
Vacío, el universo.
No hay soles, ni planetas, ni arroyos, ni montañas.
No estás tú, no, ni nadie.
Sólo una luz perdida que va hiriendo la noche.
Un pensamiento solo que corre hacia la muerte..$^{55}$

Pudiera parecer que estamos ante una visión nihilista y negativa del ser, ya que éste se fulmina cuando interpretamos que la mente muere. Sin

\footnotetext{
${ }^{53}$ Chantal Maillard, "Expresar el vacío" en La sabiduría como estética. China: confucianismo, taoísmo y budismo, Madrid, Akal, 1995, pp. 68-69.

${ }^{54}$ J. Corredor-Matheos, Metamorfosis Ponç-Kafka, Barcelona, Polígrafa, 1978, pp. 17-18.

${ }^{55}$ J. Corredor-Matheos, op. cit., p. 46.
} 
embargo, al aceptar la dualidad del ser y el no-ser, la imagen "Un pensamiento solo / que corre hacia la muerte"... es la negación de una entidad que, en realidad no existe y, que por lo tanto, no muere. Lo que resulta preciso es que la mente o el intelecto se anulen pues obstaculizan el estado de iluminación e identificación con el resto de los seres. De este modo, la disolución del yo, lejos de considerarse una experiencia negativa, resulta necesaria para entrar en sintonía con nuestra verdadera naturaleza cósmica. Pedro A. González Moreno, en su estudio sobre la poética de Corredor-Matheos titulado "Desde el silencio de la contemplación" también incide en el tratamiento de este asunto: "La experimentación del vacío no es, por supuesto, un estado de angustia existencial ni de carencias; al contrario, es una sensación de plenitud, purificante y enriquecedora." ${ }^{\prime 56}$ Se trata sencillamente de aceptar vida y muerte, ser y no-ser, como la misma cosa. He aquí el misterio de la existencia, y he aquí la aceptación serena por parte del poeta: "Si no quieres morir, / no te importe vivir." ${ }^{57}$

Alcanzar el vacío es dar el paso que nos lleva del ser al no-ser. Esto requiere, como hemos dicho, un vaciamiento interior que conlleve la anulación de la propia individualidad. Para ello, es imprescindible que el individuo se desprenda de todo cuanto alberga su yo interno: los deseos, las expectativas, las frustraciones, sus recuerdos $\mathrm{y}$, en suma, todo aquello que lo limita y condiciona, lo reafirma y define dentro de su singular personalidad. Se trata de lograr un desapego absoluto de todo cuanto forma parte de la vida, incluso de la vida en sí. El Bhagavad Gîtâ, libro a través del cual Corredor-Matheos se introduce en la filosofía oriental, en este caso de la India, está lleno de consejos que instan a vivir sin apegos. Una de sus sentencias dice: "Permanece asentada la sabiduría de aquel que no siente apego por nada, en ningún lugar, que, cuando se le presenta algo, sea bueno o sea malo, ni siente alegría ni siente aversión." ${ }^{58}$ En relación a esto, Corredor-Matheos hace la siguiente propuesta en un poema de Carta a Li-Po: “No hay ninguna razón / para estar triste / ni para estar alegre. / No hay razón para nada. / Y sé feliz así." ${ }^{59}$

\footnotetext{
${ }^{56}$ P. A. González Moreno, “Desde el silencio de la contemplación" en J. M. ${ }^{a}$ Balcells (ed.), op. cit., p. 241.

${ }^{57}$ J. Corredor-Matheos, op. cit., p. 141.

${ }^{58}$ Bhagavad Gîtâ (trad. de Francesc Gutiérrez), Los pequeños libros de la sabiduría, Barcelona, José J. de Olañeta (ed.), 2000, p. 32.

${ }^{59}$ J. Corredor-Matheos, op. cit., p. 60.
} 
El budismo habla a su vez de anular cualquier atisbo de egoísmo humano, pues éste nos aleja de la inclusión en la totalidad. Nuestra esencia o mismidad se alcanza si trascendemos a lo mundano y armonizamos con el Todo. También ellos aconsejan un despojamiento riguroso hasta la vaciedad. Veamos lo que dice uno de los maestros zen perteneciente a la ancestral Escuela de la Montaña del Este, Yuanwu (1063-1135):

Abandona todas tus fantasías, opiniones, interpretaciones y conocimientos mundanos, y renuncia a las racionalizaciones, al egoísmo y a la competitividad. Sé como un árbol seco, como la fría ceniza. Sólo cuando cesen los sentimientos, depongas toda opinión y tu mente se halle limpia y desnuda, se revelará ante tus ojos la realización zen. ${ }^{60}$

La poesía oriental, portadora de estos contenidos, también ha ejercido una fuerte influencia en Corredor-Matheos. Donald Keene, en su estudio La poesía japonesa habla de sus temas más frecuentes en relación al desapego zen: "La caída de de la flor del cerezo y la dispersión de las hojas del otoño son temas favoritos porque ambos sugieren el paso del tiempo y la brevedad de la existencia humana. Semejante poesía tiene un fondo religioso: aquel tipo de budismo que enseñó que las cosas de este mundo carecen de sentido y pronto se marchitan y que confiar en ellas es depositar nuestra fe en el polvo y la ceniza." ${ }^{61}$ Corredor-Matheos, que también repara en el otoño como estación de lo efímero, nos dice en un poema: "No pises el otoño. / Pasa sin detenerte / sobre sus secas hojas, / sobre el viejo deseo / de no vivir ya más." ${ }^{\prime 2}$ La referencia es clara: es necesario recordar nuestra condición mortal pues ésta se manifiesta como dualidad de la vida, y ambas están presentes en la totalidad de nuestro ser. De nada sirve aferrarse a este mundo. Conviene convencerse "de que todo está listo / para arder como leña, / de que todo esta noche / se volverá ceniza." ${ }^{33}$ Hay que desviar la atención de uno mismo y llevarla más allá de todo, donde el vacío.

No sólo en Oriente se ha insistido en los peligros que encierra el apego a la hora de alcanzar niveles espirituales profundos. La mística europea, igualmente conocida por Corredor-Matheos, también advierte de tal

\footnotetext{
${ }^{60}$ Thomas Cleary, La esencia del zen (Los textos clásicos de los maestros chinos), Barcelona, Kairós, 2001, p. 60.

${ }^{61}$ Donald Keene, La literatura japonesa, México, Fondo de Cultura Económica, 1980, p. 42.

${ }^{62}$ J. Corredor-Matheos, op. cit., p. 98.

${ }^{63} \mathrm{~J}$. Corredor-Matheos, op. cit., p. 66.
} 
obstaculización. El individuo ha de olvidarse de sí mismo tanto para acercarse a Dios como para llegar más allá de Él. Curiosamente, lo que está más allá de Él es el vacío. Al poeta manchego le interesan especialmente los místicos alemanes Eckhart (1260-1328) y Angelo Silesio (1624-1677). Ambos, desde su punto de vista, la ortodoxia cristiana, coinciden con el zen en profesar la existencia de una nada o vacío al que se llega después de superar el apego a todo, incluso a la religión o al mismo Dios. Estas ideas, evidentemente, no pasarían desapercibidas ante los ojos de la Inquisición. El maestro Eckhart, que ejerció como docente en París y predicó en Estrasburgo y Colonia, fue acusado de herejía y sometido a un largo proceso en el que se estudiarían algunas proposiciones extraídas de sus escritos. Entre ellas destacamos la siguiente: "Nosotros seremos transformados en Dios y convertidos totalmente en él; de la misma manera en que en el sacramento el pan es convertido en el cuerpo de Cristo, así seré yo transformado, ya que él mismo me hace su ser uno y no simplemente semejante; por el Dios vivo, en verdad, que allí no hay ninguna distinción." 64 Encontramos en estas palabras la idea de Unidad, a través de la cual se igualan todos los seres, incluyendo al mismo Dios. El Santo Oficio vería en esto la desacralización de la naturaleza divina, que se rebaja a la humana. Pero, ¿cómo acceder a esta Unidad o Todo? El maestro dice: "hay gente sobre la tierra que engendra a Nuestro Señor espiritualmente así como su madre lo engendró corporalmente. Se le preguntó quiénes eran esas gentes. Y entonces dijo: están vacías de las cosas y contemplan el espejo de la verdad y han llegado a ello sin saberlo; están en la tierra, pero su casa está en el cielo y se hallan en paz: caminan como los niños." ${ }^{65}$ El hombre, según Eckhart, es capaz de acceder a ese estado superior engendrando a Cristo en su interior, con lo cual es susceptible de ser divinizado. Para ello insta al vaciamiento interior, es decir, al desapego total, tal y como profesa el budismo, pues en éste se encuentra el estado original del ser. Pero eso no es todo; el maestro llega más allá y afirma la existencia de una Nada que es necesario alcanzar y que es anterior incluso a Dios. Su concepción acerca de la existencia del mundo es la siguiente:

Cuando estaba en mi primera causa no tenía ningún Dios y yo era causa de mí mismo; allí nada quise ni nada desee, ya que era un ser vacío y me conocía a mí mismo gozando de la verdad... Pero cuando por libre decisión

\footnotetext{
${ }^{64}$ Maestro Eckhart, El fruto de la nada, Madrid, Siruela, 1998, p. 176.

${ }^{65}$ Maestro Eckhart, op. cit., p. 147.
} 
de mi voluntad salí y recibí mi ser creado, entonces tuve un Dios; pues antes de que las criaturas fueran, Dios no era todavía Dios: pero era lo que era. Y cuando las criaturas llegaron a ser y recibieron su ser creado, entonces Dios no era Dios en sí mismo, sino que era Dios en las criaturas. ${ }^{66}$

Exceptuando la creencia en un dios, las doctrinas de Eckhart están curiosamente muy cercanas al budismo. Muchos autores así lo han señalado, por ejemplo, Suzuki, que en su estudio sobre el budismo zen comenta: "Eckhart no tuvo conocimiento alguno del budismo y Buda no tuvo conocimiento de Eckhart, no obstante, sus enseñanzas concuerdan perfectamente. Cuando leo a Eckhart me parece estar leyendo un texto budista, con diferencias exclusivamente terminológicas; en lo que respecta a la comprensión interior, coinciden plenamente." ${ }^{\prime 67}$

Otro místico al que Corredor-Matheos ha leído con atención es Angelo Silesio, médico y sacerdote, que cuatro siglos después de Eckhart, escribe ideas similares a las de éste en su libro El peregrino Querúbico. Nuestro autor destaca de él la siguiente frase, de la que comenta que es lo más alto que ha leído nunca: "Dios todavía es algo explicable, hay que llegar hasta ese desierto que está más allá de Dios." ${ }^{16}$ Como vemos, la intuición de una nada originaria más allá de Dios también anida en Angelo Silesio. En otra de sus máximas comprobamos que la ascensión del espíritu vacío o despojado de sí mismo ha de alcanzarse a través de la conducta ascética de la negación: "Nada es, sino tú y yo, y si no somos dos, tampoco Dios es ya Dios, y los cielos se desmoronan." ${ }^{69}$

La auténtica liberación del ser surge una vez se ha alcanzado el desapego absoluto a la vida. En realidad, es como si se muriese permaneciendo en ella, y es esta disposición a la muerte la que da fe de estar en ese estado, como fuera de sí. El maestro zen Huanglong (Dinastía song: 960-1279) lo expresa del siguiente modo: "Yo no moro donde habita la gente de hoy en día ni tampoco actúo como ellos. Si realmente quieres comprender lo que esto significa debes estar dispuesto a arrojarte a una pira ardiente." ${ }^{\prime 70}$ Se trata de llegar al punto más extremo: el

\footnotetext{
${ }^{66}$ Maestro Eckhart, op. cit., pp. 76-77.

${ }^{67}$ D. Suzuki, Budismo Zen, op. cit., 2003, p. 59.

${ }^{68}$ Ver entrevista de Santiago Martínez, "Corredor-Matheos, sin metáforas", en La Vanguardia, Barcelona, 27 de octubre de 2004, p. 12.

${ }^{69}$ Elémire Zolla, Los místicos de occidente III (Místicos italianos, ingleses, alemanes y flamencos de la Edad Moderna), Barcelona, Paidós, 2000, p. 394.

${ }^{70}$ Thomas Cleary, La esencia del zen, op. cit., p. 44.
} 
borde que antecede el salto al vacío. Corredor-Matheos lo conoce bien, y nos lo describe, a su manera, en el siguiente poema de $Y$ tu poema empieza:

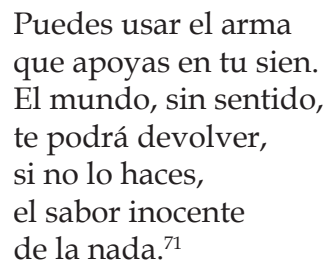

Ese "sabor inocente de la nada" es el estado de serenidad absoluta que adquiere aquel que ha perdido sus miedos, aflicciones, frustraciones, objetivos, perspectivas, etc., porque ha llegado a pensar que todo carece de valor, incluso su propia vida. Es entonces cuando su modo de existir se vuelve más natural y espontáneo, centrado en un presente inmediato que está al margen del pasado y el futuro, eternos condicionantes de la actuación. Conecta armoniosamente con el fluir del mundo y se comporta como el resto de seres que conforman la Unidad.

En las tres obras anteriores a Carta a Li-Po, pertenecientes a la etapa "Poesía de la Existencia", ${ }^{72}$ se desarrolla en cierto modo el tema de este apartado pero desde una perspectiva bien distinta. José María Balcells destaca en ellos una cosmovisión personal en torno a "la dialéctica entre la realidad de la vida y de la muerte", ${ }^{73}$ ambas caras asumidas ya como la misma cosa pero entendidas bajo el dolor y la desolación propias del existencialismo. El poeta se encuentra desamparado ante la fatalidad del ser humano que, irremediablemente solo, se enfrenta a sus propias incógnitas sin obtener respuestas que den sentido a su existencia. Los siguientes versos pertenecen al libro Poema para un nuevo libro y reflejan el estado anímico del autor: "Y yo - muerto también - / vivo con esta carga, / tan viva, de mi muerte, / sin saber esperar." ${ }^{74}$ Esta paradoja nos recuerda, sin duda, a los místicos españoles Santa Teresa de Jesús y San Juan de la Cruz, a los que Corredor-Matheos ha tenido presentes en sus lecturas

\footnotetext{
${ }^{71}$ J. Corredor-Matheos, op. cit., p. 133.

72 A. Crespo, "La poesía de Corredor-Matheos" en José Corredor-Matheos, Poesía (1951-1975), Barcelona, Plaza y Janés, 1981, p. 22.

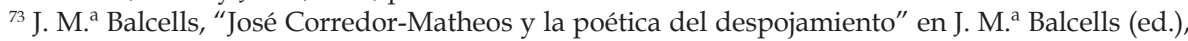
op. cit., p. 74.

${ }^{74}$ J. Corredor-Matheos, Poesía 1951-1975, Barcelona, Plaza y Janés, 1981, p.86.
} 
más tempranas: "Vivo sin vivir en mí / y de tal manera espero / que muero porque no muero." 75 Sin embargo, el poeta manchego carece de la fe en un dios que garantice la salvación eterna tras la muerte. Por eso, en vida, le sobrevienen momentos de angustia y aflicción. Muchos autores occidentales han sollozado ante la idea de un no-dios y la consecuente soledad del hombre. Se han enfrentado a un pavoroso silencio del que deducirían el absurdo y la sinrazón del ser: "En esta soledad / que me he creado / no oigo hablar otra voz / sino la mía. / Su monótono canto / sin sorpresa / aumenta este silencio."76 Por la línea que siguen estos versos, podríamos hermanarlo a César Vallejo, Blas de Otero, Dámaso Alonso, en sus libros más existencialistas, sin embargo, como dice Pedro A. González Moreno, Corredor-Matheos "nunca llega a transmitirnos una auténtica sensación de angustia, y ello se debe a que el poeta ha asumido la realidad y ha llegado a aceptarla quizá con una insatisfacción de fondo pero con un admirable estoicismo." ${ }^{77}$ Ahora bien, ¿realmente se quedaría conforme con un entendimiento del mundo ("Todo está bien ahora"), ${ }^{78}$ nacido de una gran decepción ("Y demasiadas fuerzas para nada") $)^{79}$ La respuesta es: no. La esperanza nunca muere en el poeta; se acallaba en su interior pero resurgió en cuanto tropezó con el Bhagavad Gîtâ, con la poesía china, con el budismo zen, los místicos alemanes..., que no vienen a contraponer su concepción del mundo sino a mostrar que existe la posibilidad de comprenderlo. El vacío aterrador, procedente del nihilismo existencial, arrinconaba al hombre en una orfandad fatalista. Sin embargo, esta idea da un giro circular sobre sí misma y convierte a este vacío, como hemos visto, en elemento integrador de un Cosmos unitario. Se entienden la vida y la muerte, el ser y el no-ser, como constituyentes de la verdadera y esencial realidad. El vacío es ahora, en su tercera etapa poética, respuesta complaciente y objetivo anhelado por el autor, quien se dice a sí mismo: "Quédate sin deseos / y deja que el vacío / se asiente en el vacío." 80

La constatación del no-ser recibe su forma en un poema incluido en $Y$ tu poema empieza que lleva como cita inicial o título "A modo de epitafio":

\footnotetext{
${ }^{75}$ San Juan de la Cruz, Poesía, edición de Domingo Ynduráin, Madrid, Cátedra, 1992, p. 267.

${ }^{76}$ J. Corredor-Matheos, Poesía 1951-1975, op. cit., p. 168.

${ }^{77}$ P. A. González Moreno, "José Corredor-Matheos o la asunción al nihilismo" en J. M. ${ }^{a}$ Balcells, op. cit, p. 64 .

${ }_{78}^{78}$ J. Corredor-Matheos, Poesía 1951-1975, op. cit., Véase p. 83.

${ }^{79}$ J. Corredor-Matheos, op. cit., p. 92.

${ }^{80}$ J. Corredor-Matheos, Poesía (1970-1994), op. cit., p. 132.
} 


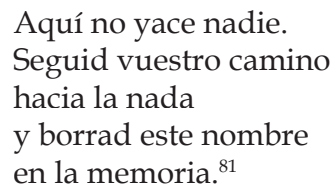

Se trata, sin duda, de todo lo que contrariamente han deseado aquellos creadores de nuestras culturas más antiguas hasta hoy: la inmortalidad. Este concepto carece de valor para el budismo pues resulta absurdo concebir la vida sin la muerte. Hay incluso que trascender a su dualismo pues se acepta que desde que nacemos estamos destinados a morir. Además, siendo portadores de ambas naturalezas (ser y no-ser), en realidad, ¿qué muere? Vida y muerte también se disuelven como uno mismo en la vacuidad. Corredor-Matheos, en un poema dedicado a la poeta norteamericana Emily Dickinson (18301886), incluso celebra el haberse librado de la cita inicial "How dreary to be somebody" (la tristeza de ser alguien):

How dreary to be somebody

Emily Dickinson

Sí, Emily, qué triste creer que eres alguien.

Qué dicha descubrir que era todo un error. Que eres esa rana cansada de croar. Que aquel a quien espera la muerte no eres tú. Pero ¿no siendo nadie, qué eres tú? ${ }^{82}$

Emily Dickinson, a quien Corredor-Matheos se siente muy cercano, es una poeta del s. XIX que fecundó su obra ahondando siempre en los niveles más profundos y esenciales del ser. También se dio a la búsqueda del sentido del mundo pero desde una soledad tanto física como referencial. Acerca de su poesía, Amalia Rodríguez Monroy comenta que "se ofrece al lector como esa vasija que el artesano ha moldeado para circundar con sus bordes el vacío y permitirnos concebirlo como lleno. Pero la artesana de esa palabra ex nihilo

${ }^{81}$ J. Corredor-Matheos, op. cit., p. 128.

${ }^{82} \mathrm{~J}$. Corredor-Matheos, op. cit., p. 134. 
nos insta además a permanecer en el borde, a seguir los contornos de su circunferencia y asomarnos, desde ahí, al vacío." 83 Los dos poetas comparten la inquietud de llegar más allá de todo, incluso de sí mismos. CorredorMatheos ya hemos visto qué camino sigue y Dickinson, rondando siempre su propia muerte, también intuye que la verdad ha de estar cerca de la autonegación. El poema anterior de Corredor-Matheos es una alusión directa al que exponemos a continuación de Emily Dickinson:

I'm Nobody! Who are you?

Are you-Nobody-too?

Then there's a pair of us!

Don't tell! They'd banish us-you know!

How dreary-to be- Somebody!

How public-like a Frog-

To tell your name-the livelong June-

To an admiring Bog! ${ }^{84}$
¡Yo soy nadie! ¿Quién eres tú?

¿Eres-Nadie-también?

¡Ya somos dos, entonces!

¡No digas nada! ¡Nos desterrarían-ya sabes!

Ser-Alguien-iQué funesto!

¡Qué vulgar!-como una Rana-

¡Cantándole tu nombre-día tras día-

A la primera Charca que te admire! ${ }^{85}$

Si se agotan las posibilidades de encontrar respuestas a preguntas metafísicas en relación al yo individual, habrá que salir de ese yo y observar más ampliamente y con mayor claridad: "Mientras mi pensamiento está desnudo-puedo distinguir, pero cuando les pongo su Vestido-parecen todos iguales y entumecidos." 86 Acaso insinuaba Dickinson que había que despojarse de ideas y pensamientos prejuiciosos que la apartaban de lo que ella intuía como esencial?: "Me from Myself-to banish / Had I Art- / . . / How have I peace / Except by subjugating / Consciousness?"87 Emily Dickinson escribió muchos poemas en los que describía no sólo su propio entierro sino todo cuanto rodeaba a la muerte. Ella descubre que es en ese límite donde su ser se muestra más completo por eso entendemos que, en cierto modo, también se acercó al vacío.

En el acto de crear, como hemos visto, el vacío adquiere un papel primordial en Corredor-Matheos. Pero anulado el yo, ¿de dónde surgen sus

\footnotetext{
${ }^{83}$ E. Dickinson, Antología bilingüe, (prólogo de Amalia Rodríguez Monroy), Madrid, Alianza, 2001, p. 8.

${ }^{84}$ E. Dickinson, op. cit., p. 80

${ }^{85}$ E. Dickinson, op. cit., p. 81

${ }^{86}$ E. Dickinson "Carta al Sr. Higginson", op. cit., p. 28.

${ }^{87}$ (Yo de Mí misma- desterrarme- / si el Don tuviera- / . . / ¿Cómo hallar paz / si no es sometiendo / A la Conciencia?) E. Dickinson, op. cit., pp. 204-205.
} 
poemas y cómo? No se crea a partir de la razón o el sentimiento; se crea a partir de la nada: esa nebulosa mágica que revela el secreto de todos los orígenes. La experiencia consiste en sentir que la obra se crea sola, procedente de ese plano superior donde operamos todos de manera unitaria. Por eso, "El paso de la creatividad a la creación exige un vaciamiento interior previo, que reducirá al creador a lo que podríamos llamar un estado de ignorancia." 88 Una vez se ha disuelto la individualidad, el autor dice que el artista introduce "cierto orden en un magma indiferenciado... en impulsos, sensaciones. No los lanza voluntariamente: los recibe y se pone en disposición de que se ordenen solos en el momento en que la mente los acepta." ${ }^{89}$

Así pues la poesía de Corredor-Matheos se origina a partir de un instinto natural innato; inmerso el autor en un estado del que en realidad participaríamos todos los seres y que, sin embargo, no todos percibimos con semejante claridad. Sus versos están ligados a la realidad más pura pero se cargan de un hondo misticismo ante los ojos del lector occidental.

${ }^{88}$ J. Corredor-Matheos, "Creación y creatividad en el arte”, Revista Nexus (núm. 25), Barcelona, Fundació Caixa Catalunya, 2000, p. 79.

${ }^{89}$ J. Corredor-Matheos, "Creación y creatividad en el arte”, op. cit., p. 79. 